\title{
Comparison of antibody detection with Blastomycesdermatitidis yeast lysate antigens in serum specimens from immunized rabbits and infected dogs
}

\author{
Will Christenson, Rachel Horton, Kayla Campbell, Kelly Meacham, Amber Schroeder, \\ Gene M. Scalarone
}

Department of Biological Sciences, Idaho State University, Pocatello, USA; *Corresponding Author: meackel2@isu.edu

Received 9 September 2011; revised 18 October 2011; accepted 8 November 2011.

\begin{abstract}
This present study was designed to evaluate $B$. dermatitidis antigens, prepared from two isolates (B5896, 597), when the yeast cells were allowed to lyse in distilled water for one day or seven days. The indirect enzyme-linked immunosorbent assay (ELISA) was used to determine the ability of the lysate reagents to detect antibodies in $\mathbf{3 0}$ rabbit and $\mathbf{3 0}$ dog serum specimens. Mean absorbance values with B5896 lysate antigen ranged from 1.637 (day 1) to 1.461 (day 7) and absorbance values with 597 antigen ranged from 1.579 (day 1) to 1.396 (day 7) with the serum specimens from immunized rabbits. Serum specimens from infected dogs yielded absorbance values ranging from 1.672 (day 1) to 1.763 (day 7) with the $B 5896$ and values ranging from 1.909 (day 1) to 1.224 (day 7) with the 597. Optimal reactivity was obtained with the day 1 lysate using both lysate antigens against the rabbit sera and with the 597 antigen against the dog sera. Slightly greater reactivity was evidenced with the day 7 B5896 antigen when the dog sera was tested. Comparative studies are continuing in order to produce an optimal antigenic preparation for antibody detection in blastomycosis.
\end{abstract}

Keywords: ELISA; Blastomycesdermatitidis; Antibody Detection; Lysate Antigens

\section{INTRODUCTION}

Blastomycesdermatitidisis a thermally dimorphic fungus that exists in a mycelial mold-like form in nature at approximately $25^{\circ} \mathrm{C}$, but when incubated at $37^{\circ} \mathrm{C}$, it survives in the yeast form $[1,2]$. The organism exists in the environment as a spore-producing mold and the spores can be inhaled into the lungs where they develop into budding yeast cells [3]. In humans, the typical route of infection is inhalation of aerosolized conidia of $B$. dermatitidis. From the respiratory tract, the developing yeast form may disseminate throughout the body and affect multiple organ systems, most commonly the lymphatic, skeletal, eyes and skin [4]. The disease can be spread throughout the body in which cutaneous lesions may occur. Up to 5 to 10 percent of disseminated cases produce meningitis or epidural/cranial abcesses; if left untreated, death may result in animals and in humans [5-7]. Blastomycosis is endemic in North America, Africa, India and parts of Europe. The majority of reported cases are from North America, primarily in the Great Lakes area as well as the Mississippi and Ohio River Valley regions $[8,9]$.

In recent years, there has been an adamant thrust in understanding the proper diagnosis of this disease because blastomycosis is often misdiagnosed that can create treatment delays [10-14]. As with many other diseases, time is of particular importance in terms of diagnosis and treatment $[15,16]$. Current culture methods may be effective, but very time consuming. Therefore researchers have focused on the development of immunodiagnostic assays in attempts to provide improved methods for the clinical diagnosis of blastomycosis in humans and animals [2,10,11,14-18]. Our laboratory has developed various $B$. dermatitidisyeast phase lysate preparations and utilized these antigens in the ELISA for the detection of antibodies in serum specimens from immunized or infected animals $[10,11,13,15]$. These studies have indicated the potential of the yeast lysate antigens as immunodiagnostic reagents, but additional studies are required in order to produce an optimal antigen for antibody detection.

The purpose of this present study was to compare the ability of B. dermatitidisyeast cell lysate antigens, prepared by lysing the cells in water for periods of 1 or 7 
days, to detect antibodies in serum specimens from immunized rabbits or infected dogs. Most of our previous comparative studies were performed with antigenic preparations following 7 days of lysis.

\section{MATERIALS AND METHODS}

\subsection{Antigens}

Mycelial phase cultures of two $B$. dermatitidisisolates (B5896 and 597) from blastomycosis outbreaks in Mountain Iron, Minnesota and Eagle River, Wisconsin were converted to yeast cells by culturing at $37^{\circ} \mathrm{C}$ on $\mathrm{BHI}$ agar. Yeast phase lysate reagents were prepared by a method similar to one that was previously used for the production of antigen from Histoplasmacapsulatum and modified in our laboratory for $B$. dermatitidislysate antigen production $[10,11,13,19,20]$. The yeast phase cells were grown for 7 days at $37^{\circ} \mathrm{C}$ in a chemically defined medium in an incubator shaker, harvested by centrifugation (700 ×g; $5 \mathrm{~min}$ ), followed by washing with distilled water, resuspended in distilled water and then allowed to lyse for 1 or 7 days at $37^{\circ} \mathrm{C}$ in water with shaking. The preparations were centrifuged, filter sterilized, merthiolate added $(1: 10,000)$ and stored at $4^{\circ} \mathrm{C}$ for further use. Protein determinations were performed on the lysates using the BCA Protein Assay Kit (Pierce Chemical Company, Rockford, IL) and dilutions of the antigenic reagents to be used in the assays were based on protein concentration.

\subsection{Serum Specimens}

Serum specimens (30) from rabbits that were previously immunized using lysate preparations of $B$. dermatitidis and serum specimens (30) from dogs with blastomycosis, provided by Dr. A.M. Legendre (University of Tennessee College of Veterinary Medicine, Knoxville, TN) were assayed. In addition 5 serum specimens from rabbits immunized with Histoplasmacapsulatum killed whole yeast cells were used in the assays to compare cross reactivity with the $4 \mathrm{~B}$. dermatitidis lysate antigens.

\subsection{ELISA}

The ability of each yeast lysate reagent to detect antibodies in the above serum specimens was determined using the indirect biotin-streptavidin enzyme-linked immunosorbent assay (ELISA). Each lysate antigen was diluted (2000 ng of protein) in a carbonate-bicarbonate coating buffer ( $\mathrm{pH}$ 9.6) and then added to triplicate wells (100 ul) of a Costar 96-well microdilution plate (Thermo-Fisher Scientific) and incubated overnight at $4^{\circ} \mathrm{C}$ in a humid chamber followed by washing three times with phosphate buffered saline containing $0.15 \%$ between 20 (PBS-T). The serum specimens (1:2500 dilution; $100 \mathrm{ul}$ ) were added to the microplate wells and incubated for $30 \mathrm{~min}$ at $37^{\circ} \mathrm{C}$. Following this incubation the wells were washed as above and $100 \mathrm{ul}$ of goat anti-rabbit or goat anti-dog IgG (H \& L) biotin labeled antibody (Kirkegaard and Perry, Gaithersburg, MD) was added to each well and incubated for $30 \mathrm{~min}$ at $37^{\circ} \mathrm{C}$. The plates were washed as above and $100 \mathrm{ul}$ of peroxidase labeled streptavidin was added to each well and incubated for $30 \mathrm{~min}$ at $37^{\circ} \mathrm{C}$ The plates were again washed as above and 100 ul of 1-step Ultra TMB-ELISA peroxidase substrate (Thermo-Fisher Scientific) was added to each well and incubated for approximately 2 min at room temperature. The reaction was stopped by the addition of sulfuric acid and the absorbance read at $450 \mathrm{~nm}$ using a BIO-RAD 2550 EIA reader.

\section{RESULTS}

\subsection{Comparison of Antibody Detection in Rabbit Sera with the Day 1 and Day 7 Lysate Antigens}

Thirty serum specimens from rabbits were immunized with $B$. dermatitidis. Two trials were performed using yeast lysate antigens (B5896 and 597) prepared on day 1 and day 7 . The results of trial 1 (Figure 1) indicated that the B5896 day 1 lysate antigen had absorbance values ranging from 1.122 to 1.759 with a mean value of 1.533 , while the range of the day 7 lysate absorbance values was 0.914 to 1.672 with a mean value of 1.269 . The second lysate antigen (597) on day 1 had absorbance values ranging from 1.155 to 1.765 with a mean value of 1.488 and day 7 values ranged from 1.008 to 1.761 with a mean value of 1.329. In trial 2 the absorbance value range of day 1 lysate antigen (B5896) was 1.556 to 1.958 with a mean value of 1.740 ; in contrast the day 7 lysate had a range of 1.498 to 1.859 with a lower mean value of 1.653. The second trial of the day 1597 lysate antigen had absorbance values ranging from 1.487 to 1.863 and a mean value of 1.669 . The day 7 absorbance values of the same antigen ranged from 1.176 to 1.856 with an overall lower mean value of 1.463 (Figure 2).

\subsection{Comparison of Antibody Detection in Dog Sera with the Day 1 and Day 7 Lysate Antigens}

Thirty serum specimens from dogs with Blastomycosiswere also assayed, as above with the rabbit sera, with the day 1 and day 7 lysate antigenic preparations. In trial 1 (Figure 3) the B5896 day 1 lysate had absorbance values ranging from 0.450 to 1.997 with a mean value of 


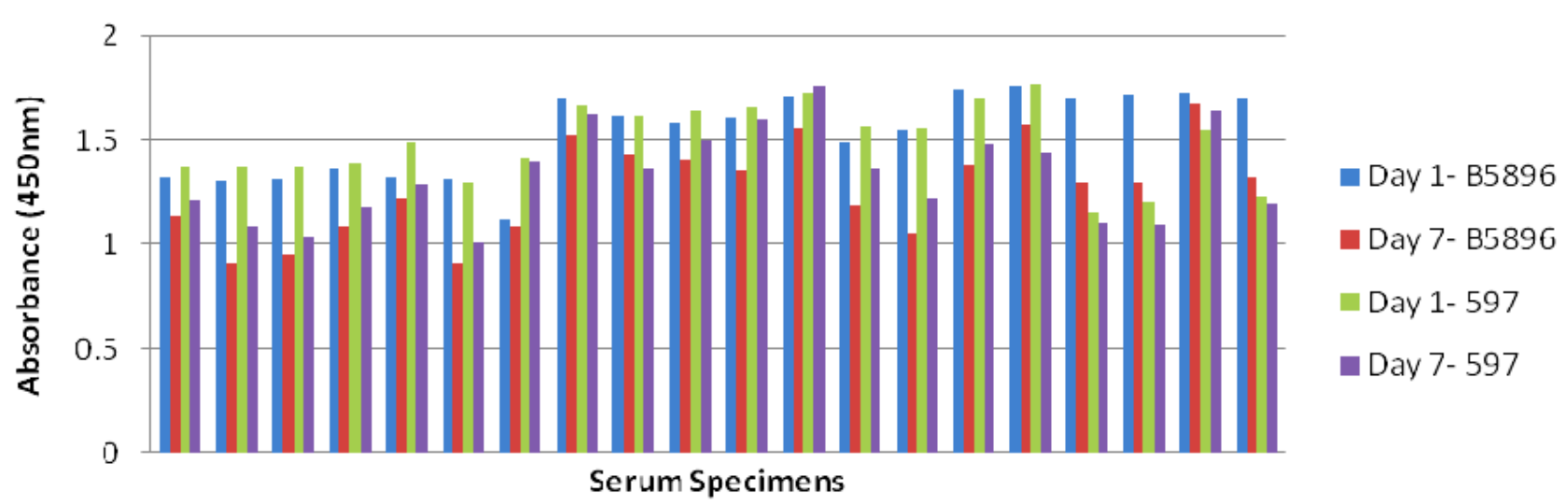

Figure 1. Trial 1 indirect ELISA mean absorbance values using 20 rabbit serum specimens with lysate antigens (B5896 and 597) prepared on day 1 and day 7

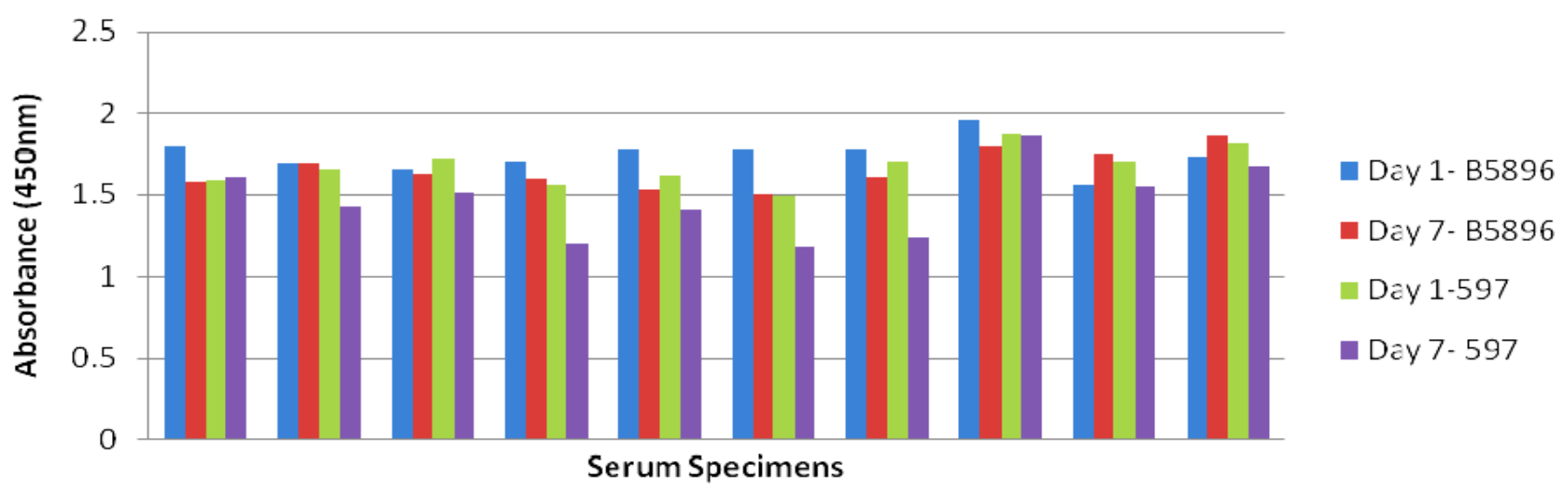

Figure 2. Trial 2 indirect ELISA mean absorbance values using 10 rabbit serum specimens with lysate antigens (B5896 and 597) prepared on day 1 and day 7.

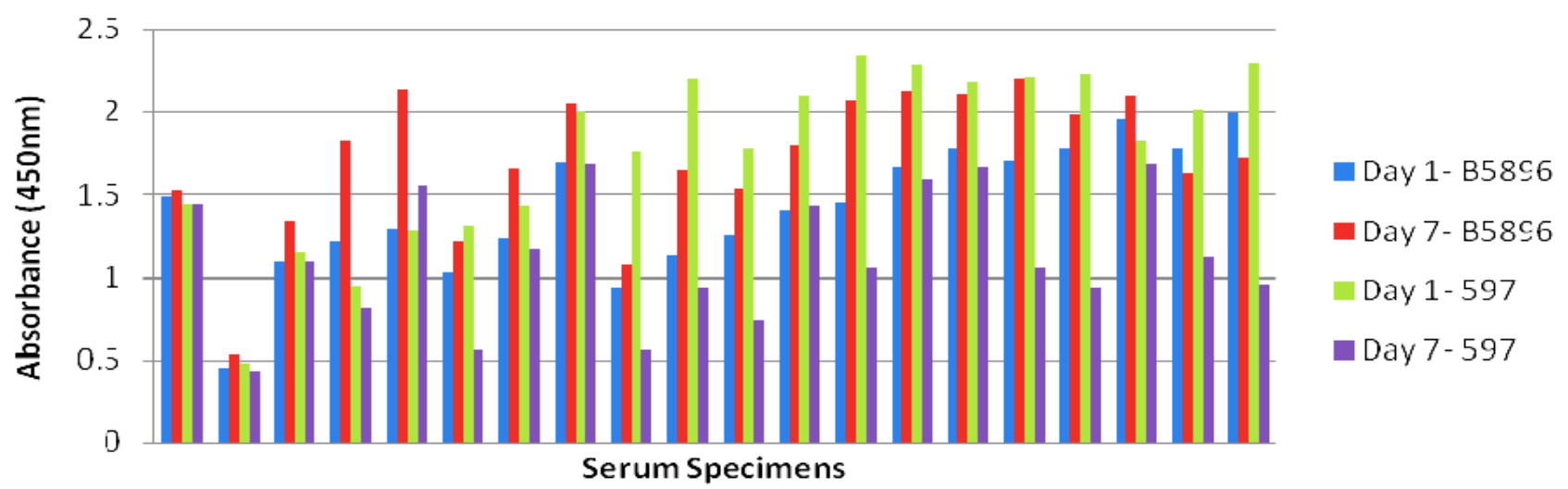

Figure 3. Trial 1 indirect ELISA mean absorbance values using 20 dog serum specimens with lysate antigens (B5896 and 597) prepared on day 1 and day 7

1.418 and the day 7 antigen values ranged from 0.529 to 2.205 with a greater mean value of 1.714 compared to the day 1 lysate. Antigen 597 day 1 values ranged from 0.480 to 2.344 with a mean value of 1.765 whereas the day 7 values ranged from 0.429 to 1.690 with a lower mean value of 1.124 when compared to 597 (day 1). Trial 2 data (Figure 4) indicated that the B5896 (day 1) absorbance values ranged from 1.427 to 2.210 with a mean value of 1.926 and the day 7 values ranged from 1.639 to 1.994 with a slightly lower mean value of 1.812 . Lysate antigen 597 (day 1) had an absorbance range of 1.630 to 2.210 with a mean value of 2.052; in contrast day 7 lysate values ranged from 0.845 to 1.720 with a much lower mean value of 1.323 . 


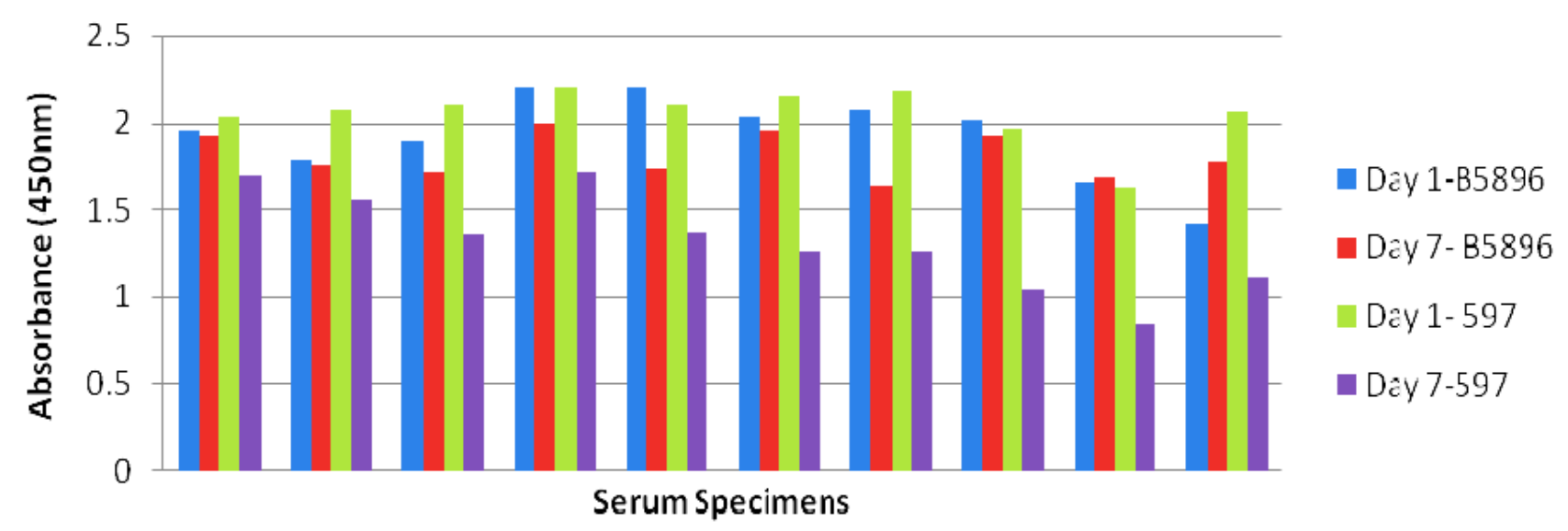

Figure 4. Trial 2 indirect ELISA mean absorbance values using 10 dog serum specimens with lysate antigens (B5896 and 597) prepared on day 1 and day 7

\subsection{Antibody Detection Mean Absorbance Values Obtained with the Day 1 and Day 7 Lysate Antigens in Sera from Rabbits and Dogs}

The antibody detection resultswith the day 1 and day 7 lysatesfrom the two trials using sera from immunized rabbits and infected dogs were combined for comparative purposes (Figure 5). All 30 rabbit serum specimens tested with B5896 lysate antigen showed a day 1 mean value of 1.637 compared to the day 7 mean value of 1.461. Thirty dog serum specimens tested using the same antigen indicated a day 1 value of 1.672 and day 7 value of 1.763 . The same 30 rabbit sera were tested using a different yeast lysate antigen (597) which yielded a mean value of 1.579 (day 1 ) while the day 7 lysate resulted in a mean value of 1.396. Lastly, the same 30 dog sera assayed with antigen 597 resulted in absorbance values of 1.909 (day 1) and 1.224 (day 7).

\subsection{Specificity Determinations with the $B$. dermatitidislysate Antigens}

Five serum specimens from rabbits that had been immunized with $H$. capsulatumwhole yeast cells were assayed with both $B$. dermatitidis and $H$. capsulatum lysate reagents in order to obtain initial evidence with regard to specificity of the day 1 and day 7 lysate antigens. As shown in Table 1, two of the B. dermatitidis preparations (Antigen 2: B5896, day 7 and Antigen 3: 597, day 1 exhibited a lower level of cross reactivity than the Antigen 1: B5896 day 1 and Antigen 4: 597 day 7 when compared to the reactivity evidenced with the homologous $H$. capsulatum antigens. As indicated above this data was obtained with a limited number of $H$. capsulatumsera and further studies are required in order to assess the specificity of the different lysate preparations.

\section{DISCUSSION}

The production and evaluation of $B$. dermatitidis yeast cell lysate antigenic reagents has been a major thrust of our research endeavors for several years. Our initial research work on the preparation of B. dermatitidis lysates was based on previous investigations on the preparation of lysate antigens for either the detection of antibodies or delayed dermal hypersensitivity in coccidioidomycosis and histoplasmosis. In studies on the development of skin-testing and serological antigens for coccidioidomycosis, Coccidioidesimmitis spherules were lysed in distilled water for a period of 40 days [19,21,22]. In contrast a one-day period of lysis of $H$. capsulatum yeast cells was sufficient to produce a reagent that detected both delayed dermal hypersensitivity as well as being useful for the detection of antibodies in the ELISA $[19,20]$. With regard to our work with $B$. dermatitidis yeast phase lysate antigens many of our comparative studies have been done with reagents following growth, harvesting and allowing the cells to lyse for a period of 7 days $[10,11,13,15,23,24]$.

The primary objective of this present comparative study was to compare yeast phase lysate reagents that had been prepared following either 1 day or 7 days of lysis in water. The lysate antigens were prepared from human isolates of $B$. dermatitidis from outbreaks in Mountain Iron, Minnesota (B5896) and Eagle River, Wisconsin (597) and assayed using the ELISA to detect antibodies in serum specimens from immunized rabbits or infected dogs. The evidence indicated that the day 1 lysates from both isolates reacted optimally with regard to detecting antibodies in the rabbit sera and the 597 day 1 lysate showed a greater degree of sensitivity than the day 7 lysate when the dog sera were assayed. In contrast the B5896 day 7 lysate exhibited slightly greater reactivity than the day 1 preparation with the dog serum specimens. 


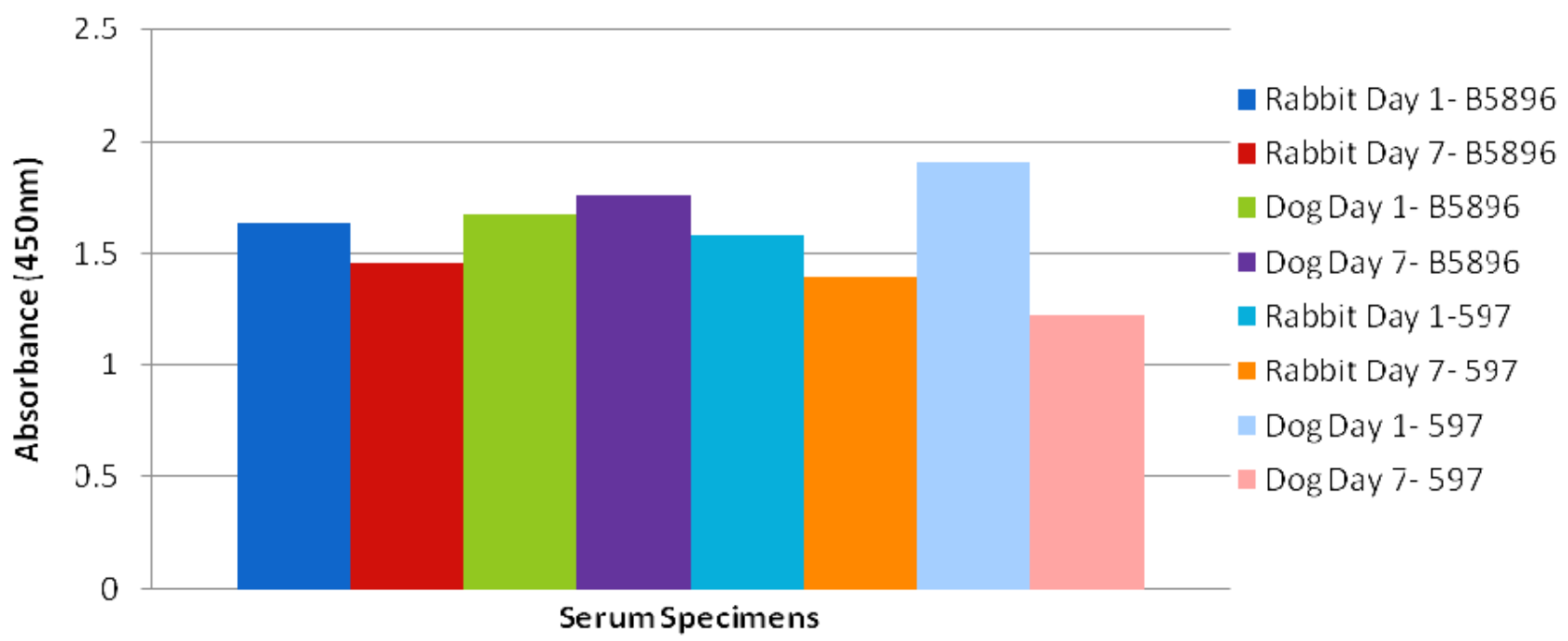

Figure 5. Combined (trial 1 and trial 2) mean absorbance values using rabbit and dog serum specimens with lysate antigens (B5896 and 597) prepared on day 1 and day 7.

Table 1. H.capsulatumserum specimens were tested with 4 B. dermatitidislysate antigens [B* = (1) B5896 (day 1); (2) B5896 (day 7); (3) 597 (day 1); (4) 597 (day 7)] and with 4 H. capsulatum lysate antigens [H* = (1) G217B; (2) G217B; (3) G217A; (4) G217B].

\begin{tabular}{ccccc}
\hline Cross-reactivity study & Antigen 1 & Antigen 2 & Antigen 3 & Antigen4 \\
\hline $\mathrm{B}^{*}$ & 1.626 & 1.597 & 1.44 & 1.535 \\
$\mathrm{H}^{*}$ & 1.713 & 1.942 & 1.83 & 1.785 \\
\hline
\end{tabular}

Therefore when the data from the above sensitivity comparisons and the specificity determinations against the limited number of $H$. capsulatum serum specimens it appeared that the day 1597 lysate antigen was an optimal reagent for antibody detection. These results indicate the potential of the day 1 lysates and also provide evidence for continuing comparative studies on the preparation of such lysates from additional $B$. dermatitidis isolates in an effort to develop lysate antigens with a high degree of sensitivity and specificity for use in the immunodiagnosis of Blastomycosis in humans and animals.

\section{ACKNOWLEDGEMENTS}

This research was supported by the Department of Biological Sciences, Idaho State University.

\section{REFERENCES}

[1] DiSalvo, A.F. (1998) Blastomycosis (Chapter 18). In: Ninth, Ed., Topley and Wilson's Microbiology and Microbial Infections. Arnold Publishers, London, 337-355.

[2] Klein, B.S. and Jones, J.M. (1990) Isolation, purification, and radiolabeling of a novel surface protein on Blastomycesdermatitidis yeasts to detect antibody in infected patients. Journal of Clinical Investigation, 85, 152. doi:10.1172/JCI114406
[3] Bromel, C. and Sykes, J.E. (2005) Epidemiology, diagnosis, and treatment of blastomycosis in dogs and cats. Clinical Techniques in Small Animal Practice, 20, 233239. doi:10.1053/j.ctsap.2005.07.004

[4] Bradsher, R.W. (2008) Pulmonary blastomycosis. Seminars in Respiratory and Critical Care Medicine, 29, 174181. doi:10.1055/s-2008-1063856

[5] Bradsher, R. W. (1997) Clinical features of blastomycosis. Seminars in Respiratory Infections, 12, 229-234.

[6] Cutler, J.E., DeepeJr, G.S. and Klein, B.S. (2007) Advances in combating fungal diseases: vaccines on the threshold. Nature Reviews Microbiology, 5, 13-18. doi:10.1038/nrmicro1537

[7] McKinnell, J.A. and Pappas, P.G. (2009) Blastomycosis: New insights into diagnosis, prevention, and treatment. inics In Chest Medicine, 30, 227-239. doi:10.1016/j.ccm.2009.02.003

[8] Bakerspigel, A., Kane J. and Schaus, D. (1986) Isolation of Blastomycesdermatitidis from an earthen floor in southwestern Ontario, Canada. Journal of Clinical Microbiology, 24, 890-891.

[9] Kesselman, E.W., Moore, S. and Embil, J.M. (2005) Using local epidemiology tomake a difficult diagnosis: A case of blastomycosis. Canadian Journal of Emergency Medicine, 793, 171-173.

[10] Axtell, R.C. andScalarone, G.M. (2002) Serological differences in three Blastomycesdermatitidis isolates. Mycoses, 45, 42-43.

[11] Axtell R.C. andScalarone, G.M. (2002) Serological differences in two Blastomycesdermatitidis isolates from different geographical regions of North America. Myco- 
pathologia, 15, 141-144. doi:10.1023/A:1014599115064

[12] Durkin, M., Witt, J., Lemonte, A., Wheat, B. and Connolly, P. (2004) Antigen assay with the potential to aid in the diagnosis of blastomycosis. Journal of Clinical Microbiology, 42, 4873-4875. doi:10.1128/JCM.42.10.4873-4875.2004

[13] Johnson, S.M. and Scalarone, G.M. (1988) Preparation and ELISA evaluation of Blastomycesdermatitidisyeast phase lysate antigens. Diagnostic Microbiology and Infectious Disease, 11, 81-86. doi:10.1016/0732-8893(88)90076-4

[14] Bradsher, R.W., Chapman, S.W. and Pappas, P.G. (2003) Blastomycosis. Infectious Disease Clinics of North America, 17, 21-40. doi:10.1016/S0891-5520(02)00038-7

[15] Bono, J.L., Legendre, A.M.and Scalarone, G.M. (1995) Detection of antibodies and delayed hypersensitivity with Rotofor preparative IEF fractions of Blastomycesdermatitidisyeast phase lysate antigens Journal of Medical and Veterinary Mycology, 33, 209-214. doi:10.1080/02681219580000441

[16] Klein, B.S., Squires, R.A., Foyer Lloyd, J.K., Ruge, D.R. and Legendre, A.M. (2000) Canine antibody response to BlastomycesdermatitidisWI-1 antigen. American Journal of Veterinary Research, 61, 554-558. doi:10.2460/ajvr.2000.61.554

[17] Vyas, K.S., Bariola, J.R. and Bradsher, R.W. (2008) Advances in the serodiagnosis of blastomycosis. Current Fungal Infection Reports, 2, 227-231. doi:10.1007/s12281-008-0033-z

[18] Spector, D., Legendre, A.M., Wheat, J., Bemis, D.,
Rohrbach, B., Taboada, J. and Durkin, M. (2008) Antigen and antibody testing for the diagnosis of blastomycosis in dogs. Journal of Veterinary Internal Medicine, 22, 839843. doi:10.1111/j.1939-1676.2008.0107.x

[19] Levine, H.B., Scalarone, G.M. and Chaparas, S.D. (1977) Preparation of fungal antigens and vaccines: Studies on Coccidioidesimmitis and Histoplasmacapsulatum. Contributions to Microbiology \& Immunology, 3, 106-125.

[20] Levine, H.B., Scalarone, G.M., Campbell, G.D., Graybill, R.C. and Chaparas, S.D. (1979)Histoplasmin-CYL, a yeast phase reagent in skin test studies with humans. American Review of Respiratory Disease, 119, 629-636.

[21] Scalarone, G.M., Levine, H.B., Chaparas, S.D. and Cobb, J.M. (1973) Properties and assay of spherulins from Coccidioidesimmitis in delayed sensitivity responses of animals. Sabouraudia, 11, 222-234. doi:10.1080/00362177385190461

[22] Scalarone, G.M., Levine, H.B., Pappagianis, D. and Chaparas, S.D. (1974) Spherulin as a complement-fixing antigen in human coccidioidomycosis. American Review of Respiratory Disease, 110, 324-328.

[23] Sestero, C.M. and Scalarone, G.M. (2006) Detection of IgG and IgM in sera from canines with blastomycosis using eight Blastomycesdermatitidis yeast phase lysate antigens. Mycopathologia, 162, 33-37. doi:10.1007/s11046-006-0028-7

[24] Shurley, J.F. and Scalarone, G.M. (2007) Isoelectric focusing and ELISA evaluation of a Blastomycesdermatitidis human isolate. Mycopathologia, 164, 73-76. doi:10.1007/s11046-007-9033-8 